\title{
Violeta Parra: tensiones y transgresiones de una mujer popular de mediados del siglo $X X^{1}$
}

\section{Violeta Parra: Tensions and Transgressions in the Mid 20th Century of a Woman from the Popular World}

\author{
por \\ Carla Pinochet Cobos \\ Universidad Autónoma Metropolitana, México. \\ carlaasecas@gmail.com
}

La obra artística de Violeta Parra presenta, en diversos niveles, una compleja problematización de los esquemas sociales de la primera mitad del siglo XX. Este trabajo busca examinar los modos en los que esta folclorista transita por los esquemas de género que recaían sobre los hombres y mujeres de la época, dando lugar a una mirada crítica e irreverente en la que la tradición cultural y la innovación confluyen, tanto en lo que respecta al contenido de sus textos como en el plano expresivo de su musicalidad.

Palabras clave: Cultura popular, género, música popular.

Violeta Parra's artistic work presents on different levels the complex problem of unraveling the social schemes of the first half of the twentieth century. This article examines the ways in which this "folclorista" moved through the gender schemes corresponding to men and women of that epoch. This movement opened a space for a both critical and irreverent view in which cultural tradition and innovation converge, both regarding the contents of her texts as well as the expression of their musicality.

Keywords Popular culture, gender, popular music.

Este artículo constituye una lectura de la obra de la folclorista chilena Violeta Parra, a la luz de los procesos sociales y culturales que experimentó nuestra sociedad durante el siglo XX. Particularmente, nos detendremos en los modos múltiples a través de los cuales Parra busca incorporar la experiencia femenina en dominios tradicionalmente de los hombres, en una búsqueda por enriquecer el imaginario del mundo popular predominante en la época. Desde su mirada femenina, pero al mismo tiempo rebelde, Violeta Parra elabora una particular síntesis artística, tanto en el plano del contenido como en la dimensión expresiva de su obra musical, en la que los roles de hombres y mujeres adquieren nuevas formas a la luz de un diálogo fecundo entre tradición y transgresión.

\footnotetext{
${ }^{1}$ Artículo basado en la ponencia presentada al IV Congreso de la Sociedad Chilena de Musicología, realizado del 7 al 10 de enero de 2007, en Santiago de Chile.
} 


\section{LA CONSTRUCCIÓN DE LA IDENTIDAD FEMENINA}

La identidad de las mujeres durante la primera mitad del siglo XX fue forjada en torno a tres pilares fundamentales promovidos a través de todos los dispositivos que la sociedad de ese entonces disponía. Por un lado, la mujer debió cuidar de su belleza física en tanto era comprendida como un correlato del cuidado y la higiene de su cuerpo. Por otro, el matrimonio y la reproducción constituían los fines superiores de la existencia femenina, encontrando así las mujeres en el ámbito doméstico y familiar un espacio natural para su correcto desarrollo.

El análisis realizado por Pabla Ávila ${ }^{2}$ de los medios de comunicación masivos del momento arroja luces esclarecedoras a este respecto. Deteniéndose en las diversas formas que adquiría la publicidad, uno de los primeros dominios específicos en términos de género, la autora descubre una serie de preceptos que los medios postulan como constitutivos de la identidad femenina: la pertenencia al hogar y al ámbito familiar, y el desarrollo de la virtud de la belleza tanto interna -a través de la bondad y moralidad-como externa -mediante el cultivo del cuerpo como objeto de cuidado-. Detrás de la promoción de estos cánones, yace una definición pedagógico-normativa del modo correcto de ser mujer.

\section{a. Gracias a Dios que soy fea...}

La belleza encontró, desde los albores del siglo recién pasado, un protagonismo que adquiría nuevas pautas y significaciones. El maquillaje, antes restringido a actrices y prostitutas, alcanzaba una generalización inédita. El cuerpo femenino comenzó a ser exhibido progresivamente, dejando atrás la opresión de los corsets y desfilando faldas cada vez más cortas. Las Cremas de oro para "un cutis lozano", los Tónicos Fru- frú para "el vigor, lozanía y mejoramiento general del ánimo", o las diversas técnicas depilatorias para "evitar los bigotes frondosos y poco atractivos", formaban parte de la nutrida parafernalia que las mujeres de la época poseían para su cuidado personal. El cuerpo de las mujeres es, entonces, el centro a partir del cual se articulan las virtudes de la identidad femenina.

En el marco de estos procesos, la biografía de Violeta Parra se encuentra signada por la tormentosa certeza de la fealdad corporal. A lo largo de las Décimas, la autobiógrafa nos guía por su recorrido vital, desde la más tierna infancia, permitiéndonos contemplar cómo el proceso de constitución de su identidad de género se encuentra atravesado por el tópico de la apariencia física. La pérdida de la belleza será un tema recurrente a lo largo de su autobiografía en versos, tal como lo expresan las siguientes estrofas:

"No se escapó ni el vacuno / de la terrible lanceta, /que la pequeña Violeta / clavó sin querer ninguno. /Tres meses pasó en ayuno / con ese terrible grano, /que le arrancó de las manos /y pies de raíz las uñas. /Su cuerpo es una pezuña, /Sólo un costrón inhumano".

2́vila 2005. 
"La niña que al tren subió / de cinta blanca en el pelo, / abrigo de terciopelo, /sandalitas de charol, /gentiles como una flor / la acompañaron por bella / por su boquita grosella, /sus ojos tan refulgentes. /Mamá emocionadamente /le da mil gracias a ellas".

"Mas, el destino traidor, /le arrebató sin piedad / por puro gusto, no más, /su bonitura y candor. / De lo que fue aquella flor, / no le quedó ni su sombra; / se convirtió en una escombra, /se le asentó la carita. /Y hasta su madre se agita/ cuando la mira y la nombra".

"Aquí principian mis penas, /lo digo con gran tristeza, /me sobrenombran "maleza" / porque parezco un espanto. /Si me acercaba yo un tanto, / miraban como centellas, / diciendo que no soy bella /ni pa' remedio un poquito. /La peste es un gran delito / para quien lleva su huella"?.

Su cuerpo marcado por la viruela será gran delito en una sociedad obsesionada con la belleza femenina. En esos años, el comercial de un jabón de marca Reuter propugnaba a través de los periódicos que "no son las facciones sino el cutis lo que hace bello el rostro". Es por ello que el rechazo que la propia Violeta siente hacia su cuerpo alcanza una agresividad tal, que es descrito como "sólo un costrón inhumano". Conforme avanza el relato, el hablante habrá de incorporar la fealdad como un atributo insoslayable, lo que le permite hacer alusión a éste a través del humor y la ironía.

\section{b. Atá' con una libreta...}

Si la belleza constituía uno de los puntales de la identidad femenina, la vida familiar puesta en marcha a través del matrimonio y la crianza de los hijos terminaba de completar el panorama. Durante el curso de la primera mitad del siglo pasado las clases dominantes demostraron en más de una oportunidad su preocupación acerca de la llamada "crisis moral" que se reproducía especialmente en los sectores populares, dada la ausencia de modelos familiares favorables al orden social. Así, desde todos los sectores y sobre todo desde el mundo eclesiástico se realizó un llamado al fortalecimiento de los lazos familiares de la sociedad popular, a través de la promoción de un modelo tradicional de familia de corte patriarcal. Éste sentaba sus bases en la supuesta predisposición femenina al ámbito doméstico y privado en tanto espacios "no contaminados por la cultura", dada la pretendida proximidad de las mujeres al estado de naturaleza. Bajo esta lógica, la adscripción femenina al espacio doméstico queda legitimada, consagrándola a los roles de madre y esposa, cuidadora del hogar y de la educación de los hijos, mientras el hombre absorbe las funciones de padre, proveedor y representante legal del grupo familiar ${ }^{4}$.

Nuevamente, la trayectoria biográfica de Violeta Parra no puede amoldarse a los reducidos límites del mundo social que le rodea. El ímpetu con el que asume su proyecto artístico se repele, en repetidas ocasiones, con la vida familiar que la época reservaba celosamente a las mujeres. Violeta contraerá matrimonio en dos

${ }^{3}$ Parra 1998: 39-47.

${ }^{4}$ Brito 2005. 
ocasiones, con Luis Cereceda, inicialmente, y con Luis Arce, después, pero ninguno de ellos perdura en el tiempo. Sus textos hacen constante alusión al matrimonio como un cautiverio femenino; como una gran atadura que condena a la mujer al sufrimiento. No puede conformarse con lo que una vida convencional puede ofrecerle: la estabilidad de una familia, una linda casa, un puntual salario.

Detrás de esa mujer sofocada por la domesticidad, había un marido tradicional que lamentaba las heridas de su orgullo masculino. Por más insoportable que le resultara la casa vacía después de una larga jornada laboral, nada podía impedir que Violeta saliera a ganar su pan en los boliches del barrio Estación. "Por ahí ya empezamos a andar mal -sostiene Luis Cereceda-, porque yo siempre fui de esa idea de que la mujer debe estar en la casa. [...] Cuando discutíamos ella siempre me decía que lo que yo quería era una empleada, no una compañera. Pero yo no podía soportar más, hasta que un día le dije: 'Bueno, sigue con tu arte, yo me voy'. Al otro día tomé mis cosas y partí" 5 .

"Verso por matrimonio", un pasaje de sus décimas autobiográficas, da cuenta de aquel proceso. En éste, Violeta Parra se rebela contra los lugares de la masculinidad popular que convirtieron su primera experiencia matrimonial en "diez años de infierno". Denuncia y condena las noches de farra y borrachera; la infidelidad; la violencia y el desarraigo. Aquellos años de sufrimientos, en los que Violeta pasó "las de Quico y Caco", encuentran una esperanza hacia el final del texto, cuando nos señala que:

"A los diez años cumplíos / por fin se corta la güincha, /tres vueltas daba la cincha /al pobre esqueleto mío, /y pa' salvar el sentí'o /volví a tomar la guitarra; / con fuerza Violeta Parra /y al hombro con dos chiquillos / se fue para Maitencillo / a cortarse las amarras" ${ }^{\text {. }}$

Aquella difícil experiencia conyugal será también elaborada en muchas de sus canciones, adquiriendo en algunas de ellas las formas y temáticas de la vida popular campesina. Particularmente gráfica a este respecto es Atención, mozos solteros, canción que les advierte a los jóvenes que el dinero no asegura la felicidad matrimonial. En ella relata las dificultades que depara la vida de casados, puntualizando que "son muy duras las cadenas a las que se van a amarrar":

"Muy cierto es que han de gozar /en los tres meses primeros, /pero después de su anhelo / hasta el nombre han de cambiar. /Tendrán que llamarse pan, /se llamarán cebollita. /También se llamará ollita /y habrá de llamarse sal /en todo esto ha de pensar /el que busca costillita. /Lo llaman platos y tazas, /y lo llaman cucharón / dirán cuando esto les pase / 'qué caro cuesta el amor'”'?.

${ }^{5}$ Luis Cereceda, en Subercaseaux, et al., 1982: 29.

${ }^{6}$ Parra 1998: 148.

${ }^{7}$ Canción: Atención, mozos solteros. Es posible encontrar este recurso discursivo en diversas localidades rurales. Las cantoras de Neuquén, zona argentina que limita con Chile, lo expresaban de la siguiente manera, esta vez dirigida a las niñas: "Cásate niña cásate/ goza los meses primeros/ y después estarás deseando/ la vida de las solteras/ Todos los meses primeros/ son dulce más que la miel/ y cuando pasa más tiempo/ son más amargo que hiel/ El hombre para casado /ningún vicio ha de tener/ y el primer vicio que saben/ es pegarle a la mujer" (Silla, 2005). 
A pesar de que su textualidad protesta en contra del canon del matrimonio, Violeta Parra conoce de cerca los imaginarios de género subsidiarios del modelo patriarcal, dada su pertenencia al tradicional mundo campesino. Así lo refleja la canción La Juana Rosa, que relata la preocupación de una madre rural acerca de su hija que, teniendo veinticinco años, aún no ha contraído matrimonio. Ante la posibilidad de tener una hija "solterona", la mujer esgrime todo tipo de argumentos para convencer a su hija de salir a "encontrar marido" en el evento social próximo (la trilla a yegua):

“No hay niña joven que no haiga / en todo este alrededor / encontrado en algun' era / alivio a su corazón. / La que lo dice es tu mama / que en l'era Juan conoció /y en l'era tu prima hermana /al mari'o que tiene hoy. /Avívate Juana Rosa / que muy ligero anda el tren /pero si vamos pá l'era /no os quedáis en el andén"8.

De la misma manera, pero esta vez a través de la ironía, Parra resume en $L a$ petaquita las pautas de género que regulan las expectativas frente al matrimonio. En ella Violeta Parra nos entrega una imagen, casi ridícula, de los hombres y mujeres de la sociedad de su época. Haciendo hincapié en cierto elemento distintivo de la vestimenta de cada género, Parra da cuenta del carácter imperativo de la vida matrimonial:

"Todos los hombres tienen en el sombrero, /un letrero que dice 'casarme quiero'. Todas las niñas llevan en el vestido, / un letrero que dice 'busco marido'"9.

La estrofa final de la canción hace reaparecer a la mujer que se niega a amoldarse a los rótulos sociales. Allí Violeta Parra desnuda el carácter arbitrario de tales mandatos, señalando que "dicen que le hace, pero no le hace", y opta por la diferencia al afirmar que "lo que nunca he tenido, falta no me hace".

\section{c. Com'esta maire ninguna...}

La empresa de disciplinamiento de las mujeres que emprendió la sociedad chilena durante principios del siglo XX se valió, además, de la promoción de la maternidad en tanto papel fundamental en la identidad femenina. En las clases populares, donde la mortalidad infantil crecía a pasos agigantados, ésta fue conceptualizada como una cuestión de orden discursivo prioritaria. Vinculando los índices preocupantes a la ignorancia y falta de higiene de las mujeres de estos sectores, se impulsó una campaña que les enseñaba cómo debían desempeñar su rol de madres ${ }^{10}$. Las mujeres no tardaron en quedar desprovistas de cualquier cariz identitario no referido directamente a su condición maternal. Las diversas instancias institucionales restringieron todo beneficio social a este tipo de mujeres, haciendo invisible el accionar femenino en otras esferas. El mundo

\footnotetext{
${ }^{8}$ Canción: La Juana Rosa.

${ }^{9}$ Canción: La petaquita.

${ }^{10}$ Brito 2005.
} 
masculino sería a partir de entonces la escena pública y el trabajo remunerado. El territorio de las mujeres, en cambio, sería el que dictaban las paredes del hogar, la intimidad y el cuidado de los hijos. Por ello, la participación femenina en el mercado laboral remunerado fue atacada bajo el argumento de que ponía en riesgo la integridad moral y física de la madre y sus retoños. Además de incentivarles el abandono de sus tareas maternales, el trabajo de las mujeres era considerado una competencia para los hombres, ya que los patrones preferían emplearlas a ellas: percibían salarios menores y eran más sumisas ${ }^{11}$.

Incluso en círculos feministas, como es el caso de la publicación obrera $L a$ Palanca $^{12}$, el rol de las mujeres en el escenario social es visto, en gran medida, a través del prisma de la función reproductora. A pesar de que no se le considera la máxima contribución femenina, aparecen en ella continuas alusiones al aporte que los hijos de las obreras harán al proceso revolucionario ${ }^{13}$. Nuevamente, la mujer proyecta su importancia social a través de su rol de madre. A este respecto, resulta interesante recordar una canción de Violeta Parra titulada Hace falta un guerrillero. En ésta, la cantautora reproduce la lógica de las obreras que aquí señalamos, al hacer manifiesto su deseo de tener un hijo capaz de encarnar los valores de la patria como, en su oportunidad, lo hizo Manuel Rodríguez. La figura femenina no invoca las virtudes del guerrillero, en este discurso, para ejercerlas por sí misma, sino, por el contrario, las pide para un hijo que sea capaz "de enseñar al cobarde a amar y corresponder"14.

"Quisiera tener un hijo / brillante como un clavel, / ligero como los vientos, / para llamarlo Manuel, /y apellidarlo Rodríguez, / el más preciado laurel. / De niño le enseñaría / lo que se tiene que hacer / cuando nos venden la patria / como si fuera alfiler; /quiero un hijo guerrillero /que la sepa defender"15.

La biografía de Violeta será un continuo intento por apartarse de esta moral promovida socialmente que, sin embargo, introyecta. Formulándolo con las palabras de Carlo Ginzburg ${ }^{16}$, podemos señalar que "de la cultura de su época, y de su propia clase, nadie escapa sino para entrar en el delirio". Ello no significa que las pautas sociales no puedan ser transgredidas, sino, por el contrario, que aquellas transgresiones dialogan constantemente con el "deber ser" de la época, bajo la forma de tensiones, frustraciones y culpas. Violeta Parra encarna la clásica incom-

${ }^{11}$ Brito 2005.

${ }^{12}$ Publicación feminista de propaganda emancipadora puesta en circulación a partir de 1908, que surge al interior de la Asociación de Costureras para promover la protección, el ahorro y la defensa.

13 Ávila 2005.

${ }^{14}$ En el IV Congreso Chileno de Musicología (2007) se me hizo una observación muy pertinente con respecto a este tema. Se me señaló que detrás de la inquietud que demuestra Violeta con esta canción, reside la búsqueda de un Mesías redentor capaz de poner freno a la injusticia en la tierra. La metáfora mesiánica presenta, no obstante, la misma lógica antes señalada. La encarnación de un modelo mariano que dictamina un rol pasivo e indirecto de la mujer frente al cambio social, proyectando su importancia a través de la crianza de los hijos varones.

${ }^{15}$ Canción: Hace falta un guerrillero.

${ }^{16}$ Ginzburg 1976. 
patibilidad femenina entre la maternidad y el desempeño laboral, el cual en su caso coincide con un proyecto artístico-cultural que absorbe gran parte de su energía. El compromiso que la folclorista siente con su labor de recopilación y difusión del patrimonio cultural campesino terminará por superponerse a sus responsabilidades maternales, invirtiendo el sentido tradicional de la relación madre/hijos. Según lo señalan sus hijos mayores, Isabel y Ángel, la infancia que ellos tuvieron se encontró siempre supeditada al proyecto de Violeta. Desde pequeños fueron impulsados a aprender de música, instrumentos, bailes y presentaciones, con el objeto de algún día llegar a concretar la obstinada idea de su madre de que toda la familia se desempeñara como un conjunto artístico.

Sin embargo, el modelo familiar llevado a cabo por Violeta Parra no será impermeable a los influjos que la sociedad androcéntrica introyecta en las mujeres. La relación de Violeta con la menor de sus hijos, Rosita Clara, marcará un hito indeleble en esta trayectoria de la culpa. La folclorista es invitada por el Partido Comunista al Festival de las Juventudes de Varsovia, Polonia. Emprende el viaje a Europa, dejando atrás a su marido y sus hijos, estando la menor de ellos aún en la cuna. Sus décimas autobiográficas expresan la aprensión que este viaje le sugiere:

"Dejo bot'a mi nación, /mis crías y mi consorte, /ya tengo mi pasaporte /me está esperando el avión: / penetrando en l'estación /un seremil de personas /me ruedan como corona / al verme sumida en llanto / porqu'era mucho el quebranto / al partir para Polonia".

"De nueve meses yo dejo / mi Rosa Clara en la cuna; /com'esta maire ninguna, /dice el marí'o perplejo; /voy repartiendo consejo /llorando cual Maudalena, /y al son que corto cadena /le solicito a Jesús / que me oscurezca la luz /si esto no vale la pena"17.

A medida que avanza el relato, es posible observar la trayectoria de la culpa de una madre que se aparta de su hija. Operan en esta secuencia las pautas de una sociedad que, además de reducir la feminidad a la expresión de la belleza y el sentimiento maternal, se encuentra fuertemente marcada por una lógica católica del castigo y el arrepentimiento. En la textualidad de Violeta Parra, esta tradición aparecerá con frecuencia, e incluso, algunas veces, la referencia al discurso católico y sus resonancias escatológicas adquirirán importantes niveles de explicitud:

“...Pocos serán los desvelos, /dice l'orar profetorun, /p’aquella que su angelorum / deja botá' en el invierno, /arrójenla en los infiernos /p’a sécula seculorum”18.

En este marco, cobra importancia la figura de la Virgen María como la encarnación de todos los valores femeninos considerados positivos, entre ellos, por supuesto, los que se refieren a la maternidad: abnegación y sacrificio. Es justamente a esta Virgen a la que apela la hablante, al verse acongojada por la pérdida de su niña. Como lo expresa el siguiente extracto de una canción, Violeta recurre a la Virgen para obtener un consuelo y un perdón para su tristeza:

\footnotetext{
${ }^{17}$ Parra 1998: 160.

18Parra 1998: 160.
} 
“...Perdóname gran Señora, / digo a la Virgen María, / no ha sido por culpa mía, /yo me declaro inocente, / lo sabe toda la gente / de que no soy mala maire, /nunca p'a ella faltó el aire / ni el agua de la vertiente"19.

Mientras el alma de la mala madre "vive en pecado mortal" y "no tiene perdón de los cielos", su cuerpo desacralizado le resulta cada vez más deshonroso. Las acciones o productos de los cuerpos de las mujeres pertenecen a un territorio intocable en la medida que se vinculan al acto supremo de la maternidad. Por ello, una vez que quedan desprovistos de esa significación, rayan en lo abyecto y despreciable. La hablante se humilla en su condición de madre al tildar de "mentira el dolor que siento, como parto sin recelo". De la misma forma, el "sagrado alimento" que emana de sus pechos, una vez lejos de la legítima lactante, no puede ser sino leche indigna que recuerda la lejanía.

"M'encamino al hospital /a dejar mi lech'indina; /los pechos se me lastiman /con el sagrado alimento, / teniendo el convencimiento / que d'hambre llora en la cuna /la que sin culpa ninguna /dejé sin remordimiento" 20 .

Su hija Rosita Clara muere de una pulmonía 28 días después de su partida. A partir de entonces Violeta escribía, semanalmente, dos tarjetas a su marido Luis Arce culpándolo sistemáticamente de la muerte de Rosita Clara. Escribió, además, canciones y poemas expresando el dolor de esta partida.

"Cuando yo salí de aquí / dejé mi guagua en la cuna / creí que la mamita Luna / me la iba a cuidar a mí, / pero como no fue así / me lo dice en una carta /p'a que el alma se me parta / por no tenerla conmigo; /el mundo será testigo / que hei de pagar esta falta ${ }^{21}$.

A pesar de la tristeza profunda que esta experiencia de viaje implica, el abrirse a nuevos mundos será una instancia crucial en la formación de Violeta Parra. Los viajes femeninos, incluso en la reducida expresión que adquirieron durante el transcurso de la primera mitad del siglo XX, constituyeron para ellas un quiebre en la reclusión doméstica, que les permitió una mayor apertura al mundo. Atravesadas por las territorialidades de clase, las incursiones de las mujeres en el espacio público cobraban la forma de viajes de caridad, en el caso de la aristocracia, y viajes laborales, en el caso de las capas inferiores ${ }^{22}$. Violeta Parra, sin embargo, experimentó una categoría de viaje celosamente reservada al género masculino: la gira. En una sociedad como la suya, optar por ello implicaba necesariamente abandonar el espacio doméstico y postergar el proyecto familiar. La decisión con que Violeta enfrentó esa disyuntiva es la que hace posible hoy que, a cuarenta años de su muerte, conozcamos todavía el legado de su trabajo.

\footnotetext{
${ }^{19}$ Canción: Versos por la niña muerta.

${ }^{20}$ Parra 1998:161.

${ }^{21}$ Canción: Versos por la niña muerta.

${ }^{22}$ Ávila 2005.
} 


\section{HERENCIAS Y TRANSGRESIONES EN LA DIMENSIÓN EXPRESIVA}

En su dimensión formal, la obra de Violeta Parra problematiza las fronteras de género que rigen la expresión musical de aquella época. Por un lado, su trabajo transita con soltura por los territorios que la tradición asigna al mundo masculino y al femenino en las zonas rurales. Por el otro, la puesta en escena con que Violeta da a conocer su obra al público cuestiona fuertemente los estereotipos de género que predominan en el medio del espectáculo y la industria musical. Violeta Parra no se ciñe a los dictámenes que la sociedad impone a su género. Su obra, por el contrario, es el producto de tránsitos, fusiones, herencias y transgresiones expresivas que problematizan el rol femenino tanto en la música tradicional de corte folclórico como en la industria del espectáculo.

Violeta Parra inicia su trayectoria como folclorista retomando la figura de la cantora popular que, pese a su rol central en el mundo festivo campesino, perdía importancia entre las manifestaciones folclóricas trasvasijadas a la ciudad. De esta manera lo observa Gastón Soublette, quien sostiene que "lo que se escuchaba fundamentalmente en música chilena eran tonadas, pero no cantadas en su sentido auténtico, sino que en un estilo de boite, a lo Pollo Dorado". Persistían, eso sí, algunas representantes urbanas de las "cantoras legítimas", que sin embargo alternaban la veta tradicional con la música popular de ese momento. "Entonces -continúa Soublette-, lo folclórico se perdía. Y en medio de todo esto, aparece una voz un poco gastada, como es la voz típica de la campesina nuestra, una voz baja, con pocas modulaciones, la de Violeta Parra"23.

Sin embargo, la propuesta musical de Violeta Parra no coincidía del todo con la figura de la cantora popular, puesto que ellas, en el modelo más clásico, se limitaban a interpretar sólo algunas formas del cantar campesino. El canto de Violeta Parra no dejaba a todos contentos, sobre todo en los círculos de cantores populares. A nuestro juicio, esa desavenencia guardaba relación con la postura un tanto irreverente que presentaba Violeta en cuanto a los papeles que asumían hombres y mujeres en este medio artístico. Como advierte Margot Loyola en el libro Gracias a la vida:

\footnotetext{
"El canto a lo poeta estaba definido a mediados del siglo XVIII como canto masculino, era propio del cantor popular que canta décimas acompañándose con el guitarrón y posteriormente con guitarra. Y el otro canto folclórico, la tonada, la canción que no es con décimas, el acompañamiento de las danzas, ése era el canto de la mujer. Pero con el correr del tiempo también cantaron mujeres el canto con décimas, aunque tampoco esto era muy frecuente. Y la Violeta es de las que incursionó mucho en esta rama del canto y la interpretó bien" 24 .
}

No hemos podido encontrar, hasta la fecha, muchos estudios que se ocupen de los roles de género en la poesía y música popular campesina. Sin embargo, es posible señalar algunas consideraciones generales a este respecto. Tal como lo

\footnotetext{
${ }^{23}$ Gastón Soublette, en Subercaseaux et al. 1982: 54.

${ }^{24}$ Margot Loyola, en Subercaseaux et al. 1982: 46.
} 
señala Rodolfo Lenz en la siguiente cita, y como se ve reflejado en Cantos folclóricos chilenos (1979), hombres y mujeres del mundo artístico rural desempeñaban funciones distinguibles grosso modo.

"Es un rasgo mui característico de la poesía popular chilena el que se divida rigurosamente en una rama masculina i una femenina. Cada una de ellas tiene sus argumentos, su métrica, su canto i sus instrumentos particulares i propios. Es común a ambas ramas que el canto se hace casi siempre en voz mui aguda; las mujeres usan de preferencia el falsete, lo que produce una impresión estraña al oído alemán. Las cantoras cultivan casi exclusivamente la lírica, liviana, el baile i cantos alegres en estrofas de cuatro 4, menos a menudo, de cinco versos; sus instrumentos son el arpa i la guitarra. Los hombres, en cambio, se dedican a los escasos restos del canto épico (romances), la lírica seria, la didáctica i la tenzón controversia poética, llamada "contrapunto". La forma métrica preferida es la décima espinela, su instrumento el sonoro 'guitarrón”"25.

El canto a lo poeta, en cualquiera de sus versiones ${ }^{26}$, suele considerarse una atribución masculina, como también así sucede con los duelos de payas ${ }^{27}$. Por su parte, las mujeres suelen ser cantoras de tonadas, cuecas y parabienes, interpretando además una diversidad de versos según las distintas ocasiones. Entre los hombres, un poeta o cantor popular debe destacarse por su virtuosismo, habilidad y elocuencia, exhibiendo al público oyente una amplia variedad de fundamentos en sus versos ${ }^{28}$. En consecuencia, el arte varonil es de carácter individual, y debe ejercerse -directa o indirectamente- en contra de un oponente, adquiriendo una connotación "bélica" que desaparece en el cantar femenino. El canto de las mujeres, por su parte, se vincula estrechamente con la dimensión festiva de la vida campesina, ya que su ocasión principal es la animación de fiestas y eventos comunitarios. Una buena cantora puede jactarse de que hace bailar a la más tímida concurrencia. La Cueca del balance grabada por Violeta Parra encarna, en este sentido, la más tradicional veta de las cantoras populares, ya que su objetivo es justamente convocar a los presentes a la pista de baile:

"Mi vida, /qué están haciendo mirones /ay morenito, ay moreno /que no salen a bailar. /ay morenito, ay moreno / que no salen a bailar. /Mirones no querimos, / mi vida, / por estos lados / ay morenito, ay moreno / mi vida, dijo el cuñado / ay morenito, ay moreno / mi vida, por estos lados ${ }^{29 "}$.

${ }^{25}$ Lenz 1918.

${ }^{26} \mathrm{El}$ canto a lo poeta, antigua tradición nacional de más de 400 años, es una manifestación del arte campesino aún vigente en la zona central del país. Puede describirse como poesía cantada, que cobra las formas de cuarteto, copla o décima espinela, cuya fórmula métrica es ABBAACCDDC. Existen dos vetas dentro de éste: el canto a lo divino y el canto a lo humano. Es una tradición familiar que se reproduce de generación en generación (Astorga 2000).

${ }^{27}$ La paya, voz quechua que quiere decir "dos", es una de las vertientes del canto a lo humano, y consiste en un duelo improvisado entre dos cantores a lo poeta.

${ }^{28}$ Esto aplica especialmente al caso del canto a lo humano y las payas. El canto a lo divino responde más bien a la devoción de sus intérpretes, por lo cual los juicios de esta índole no tienen lugar. En éste, los temas están establecidos.

${ }^{29}$ Canción: Cueca del balance. 
En concordancia con este carácter festivo, el arte de las cantoras populares no se corresponde con un culto a la personalidad, sino, por el contrario, permite la existencia de dúos y tríos de mujeres animando las fiestas. En efecto, la Cueca del balance es una de las pocas canciones que Violeta Parra grabó en compañía de otra cantora. Con todo, es importante señalar que existían casos ya entonces, y por supuesto, muchos más en la actualidad, de mujeres que se desempeñaran en el canto a lo poeta, o de hombres que incursionaran en la animación cantada de fiestas, pero en su mayoría respondían a circunstancias excepcionales.

La suma de todos estos imaginarios de género hizo hostil, en cierta medida, la entrada de Violeta Parra al mundo de los poetas y cantores populares. Parra interpreta, en reiteradas ocasiones, los motivos del canto a lo poeta, promoviendo canto a lo humano y lo divino en el mundo radial. Incursiona, además, en la escritura de décimas espinelas con su autobiografía, hecho que la sitúa en un territorio doblemente masculino. Primero, porque las décimas correspondían tradicionalmente al mundo varonil, y segundo, porque el acto escritural fue ejercido, históricamente, por hombres, configurando un espacio de expresión de las grandes hazañas y no de las pequeñas domesticidades. Aún así, el trabajo de Violeta en estas esferas no le restringe el ejercicio de la tradición femenina, ya que su repertorio estará compuesto, en importante medida, por tonadas, cuecas y parabienes. Incorporará las temáticas interpretadas por las cantoras populares, siendo el asunto amoroso, trabajado con sensibilidad y talento, uno de los grandes puntales de su obra.

Sin embargo, no son, a nuestro juicio, todos aquellos desplazamientos los que vuelven problemática la aparición de Violeta en este medio, sino más bien la actitud con la cual ella se presenta. Violeta exige silencio para iniciar su presentación y no se amilana ante nada mientras dura su performance. Exhibe su trabajo ante los presentes, demostrando la calidad de éste con una actitud fácilmente homologable a la desafiante postura masculina. Entra en el juego, en definitiva, del virtuosismo de los cantores populares, apartándose en este sentido de la modestia y humildad de las cantoras. Este tinte de competencia y desafío posiciona la obra de Violeta Parra en el lugar de la transgresión.

Pero toda la impronta desafiante que sugiere el trabajo de esta folclorista contrasta, por otra parte, con la sencillez de su apariencia física. Su estilo austero y descuidado insertaba la imagen de la mujer popular campesina en el mundo de la radio y el espectáculo, apartándose de las demandas que la industria cultural imponía por aquellos años a las ya mencionadas artistas del folclore. Así como dentro de los marcos del universo campesino, tampoco en los parámetros comerciales y masivos la figura de Violeta Parra se adscribirá a los cánones femeninos. Como señala Rodrigo Torres, despojándose de todo artificio, "ella misma se liberó en el escenario del estereotipo de lo femenino que obligaba a la mujer a un permanente rol sensual y seductor" 30 . Considerando la importancia que la belleza, gracia y picardía tenía para la identidad femenina de aquellos años, podemos explicarnos el asombro que generaba la presencia de Violeta Parra en la escena

${ }^{30}$ Torres 2004. 
musical femenina. Creemos que el testimonio de su hijo Ángel es particularmente decidor a este respecto:

"Lo que ella hizo fue tomar la guitarra y empezar a cantar sin preocuparse de los atuendos, sin maquillaje y sin adoptar una pose exterior de figura "folclórica" al uso oficial. Y dándole una presencia protagónica en el canto a la mujer, porque hasta ese momento los conjuntos eran predominantemente masculinos. Si algún día alguna mujer se dedica a estudiar el proceso de liberación femenina en Chile, tendrá que tomar en cuenta el rol de Violeta Parra en ese momento histórico. No porque haya teorizado o escrito artículos sobre el tema, sino por su actitud"31.

Efectivamente, creemos que es la actitud de Violeta Parra la que le permite problematizar la labor femenina en el ámbito de la música folclórica, tanto tradicional como masiva. Será esa particular forma de ser mujer la que le permitirá crear una "musicalidad alternativa", determinada por una comunicación fluida con su público, que anula la brecha entre la artista y los oyentes ${ }^{32}$. Esta atmósfera íntima y cercana, profundamente marcada por su sensibilidad femenina, es capaz de dar lugar a una comunidad entre emisor y receptores que recuerda y remite a la oralidad. La proximidad a este sistema de expresión aparece con frecuencia en sus décimas autobiográficas, en las cuales se dirige, cariñosamente, a sus "señores oyentes".

\section{REFLEXIONES FINALES}

Recapitulando el análisis, a lo largo de estas páginas hemos visto cómo la figura de Violeta Parra, tanto desde el punto de vista biográfico como en lo que respecta a su producción artística, se encuentra atravesada por una reflexión en torno a la identidad femenina. Violeta se enfrenta a los modelos de mujer que predominan en la sociedad de la época, ya sea en el mundo rural o en la vida urbana. Su trabajo constituye, desde múltiples puntos de vista, una elaboración de las problemáticas que aquejan a su género, que da lugar a una síntesis particular que en algunos aspectos se ciñe a la tradición, y en otros la subvierte o cuestiona. Es de esta forma cómo, condicionada por una experiencia urbana de liberación femenina, Violeta se rebela contra la actitud pasiva y modesta de las cantoras campesinas, al mismo tiempo que, siendo ferviente defensora del bajo pueblo, reivindica las imágenes de la mujer popular y se opone a los ostentosos atuendos de las artistas del folclore.

Creemos que no es posible entender la vida y obra de Violeta Parra a partir de la tradición o la transgresión, en forma separada. Su trabajo responde, sin duda, a un diálogo fecundo con cada uno de ellos, en el cual tiene lugar una suma de desplazamientos y fusiones que le imprimen a su obra un sello inconfundible. En cuanto al proceso de construcción de su identidad femenina, no debe caerse en el error de entenderlo por completo desde la negación y la diferencia; parte fun-

\footnotetext{
31 Ángel Parra, en Epple 1987: 123-124.

${ }^{32}$ Torres 2004.
} 
damental de lo que conocemos hoy día de ella se basa, justamente, en una sensibilidad femenina que Violeta trabajó ejemplarmente. Su iniciativa se orienta, por el contrario, a generar nuevos espacios en el masculinizado medio de los sectores populares, donde las formas y experiencias femeninas puedan ser acogidas sin fronteras ni tapujos. La integración de estas sensibilidades en el imaginario del mundo popular constituye una directriz fundamental en la obra de Violeta Parra.

\section{BIBLIOGRAFÍA}

\section{Astorga, Francisco}

2000 "El canto a lo poeta", RMCh, LIV/194 (julio-diciembre), pp. 56-64.

ÁvILA, PABLA

2005 Irrupciones de mujeres y discursividades de lo(s) femenino(s) a principios del siglo XX en Chile. Tesis para optar al grado de Magister en Estudios de Género y Cultura, mención Ciencias Sociales. Santiago: Facultad de Ciencias Sociales, Universidad de Chile.

Brito, Alejandra

2005 De mujer independiente a madre, de peón a padre proveedor. La construcción de identidades de género en la sociedad popular chilena, 1880-1930. Concepción: Ediciones Escaparate.

Epple, Juan Armando

1987 "Entretiene avec Angel Parra" [Preguntas por Violeta Parra], Caravelle. Cahiers du monde hispanique et luso-brésilien, $\mathrm{N}^{\circ} 48$, pp. 121-126.

Ginzburg, Carlo

1976 El queso y los gusanos. El cosmos según un molinero del siglo XVI. D.F, México: Editorial Océano.

LENZ, Rodolfo

1918 Sobre la poesía popular impresa de Santiago de Chile: Contribución al folklore chileno. Separata de Anales de la Universidad de Chile.

OSSANDÓn, CARLOS

2005 El estallido de las formas. Chile en los albores de la cultura de masas. Santiago de Chile: LOM Ediciones.

PARRa, Violeta

1979 Cantos folclóricos chilenos. Santiago de Chile: Editorial Nascimento.

1998 Décimas. Autobiografía en verso. Santiago de Chile: Editorial Sudamericana.

Silla, Rolando

2005 "Las Cantoras. Género y tradición en el Alto Neuquén”, Diálogo Antropológico III/ 12, pp. 69-78.

Subercaseaux, Bernardo, Patricia Stambuk y Jaime Londoño

1982 Gracias a la vida. Violeta Parra, testimonio. Santiago: Graniza/Ceneca.

TORRES, RODRIGO

2004 "Cantar la diferencia. Violeta Parra y la canción chilena", RMCh, LVIII/201 (enero-junio), pp. 53-73. 